\title{
The Effect of McConell Tape on Patients with Patellofemoral Pain
}

\author{
Hyung-pil Jun ${ }^{1}$, Eunwook Chang ${ }^{2}$ \\ ${ }^{1}$ Department of Physical Education, Dong-A University, Busan; ${ }^{2}$ Department of Kinesiology, Inha University, Incheon, Korea
}

PURPOSE: Patellofemoral pain is a common overuse injury in knee joint among runners. McConell taping technique has been recommended to alleviate symptoms in patients with patellofemoral pain. However, the clinical effects of McConell taping are not welldescribed. Therefore, we reviewed the effect of McConell taping in reducing patellofemoral pain.

METHODS: In this review, we summarized the effect of McConell taping on pain management, muscular function, proprioception, and functional task performance.

RESULTS: Application of a standard McConell taping technique to patients with patellofemoral pain showed a positive effect on pain management. However, there are limited investigations about proprioceptive improvement after taping. In addition, there are controversial results on vastus medialis and vastus lateralis EMG activity and functional task performance.

CONCLUSIONS: Understanding effectiveness and mechanism of McConnell taping is important to provide evidence to clinical professionals. As we reviewed and summarized many different studies, controversial findings exist in scientific and clinical studies. Therefore, it is recommended that future investigations into McConnell taping should focus on these factors to provide more consistent effects so that many clinicians can use McConnell taping technique with evidence.

Key words: Anterior knee pain, Patellofemoral joint, Treatment, Taping technique

\section{INTRODUCTION}

Patellofemoral pain (PFP) is one of the most common overuse injuries among runners who visit outpatient sports medicine clinics [1]. The term PFP is usually defined as a condition of anterior knee pain. This pain is normally evident after prolonged sitting, squatting, kneeling, and stair ascent and descent [2]. It is believed that these activities increase patellofemoral joint (PFJ) reaction forces and PFJ stress [3]. The etiology of PFP is not clearly understood and the risk factors have been reported to be multifactorial including onset timing of vastus lateralis and vastus medialis muscle, structural abnormalities, imbalances in muscle strength, and anomalous kinematic variables [4-7]. Lower extremity malalignment is caused by increased Q-angle, excessive pes planus, and/or excessive subtalar pronation; and it is known to be one of the major factors causing PFP [8-10]. However, the evidence supporting the relationship between static lower extremity malalignment and lower extremity injuries is limit- ed and remains controversial. The PFJ includes the articulation of the femoral trochlea and the patella. The patella provides an important role within the knee joint, acting as a lever and increasing its moment arm. Due to the nature of this joint structure, the patella is connected and stabilized by many structures. Stability is provided from dynamic and static stabilizers. These stabilizers control the movement of the patella over the femoral trochlea referred to as patellar tracking. The distribution of imbalanced stabilizing forces [11] can result in altered patellar tracking (abnormal patellar tracking) along the femoral trochlear groove. Particularly, imbalance between the vastus medialis oblique $(\mathrm{VMO})$ and vastus lateralis $(\mathrm{VL})$ due to either VMO dysfunction or tightness of the lateral stabilizers can cause lateral patellar tracking, known as the "J"-sign, as the knee is extended from $90^{\circ}$ flexion to full extension (Fig. 1). Therefore, restoration of abnormal patella tracking by using taping techniques have been recommend to use and the current manuscript reviewed the effect of specific taping technique (McConnell tape) for PFP patients. 

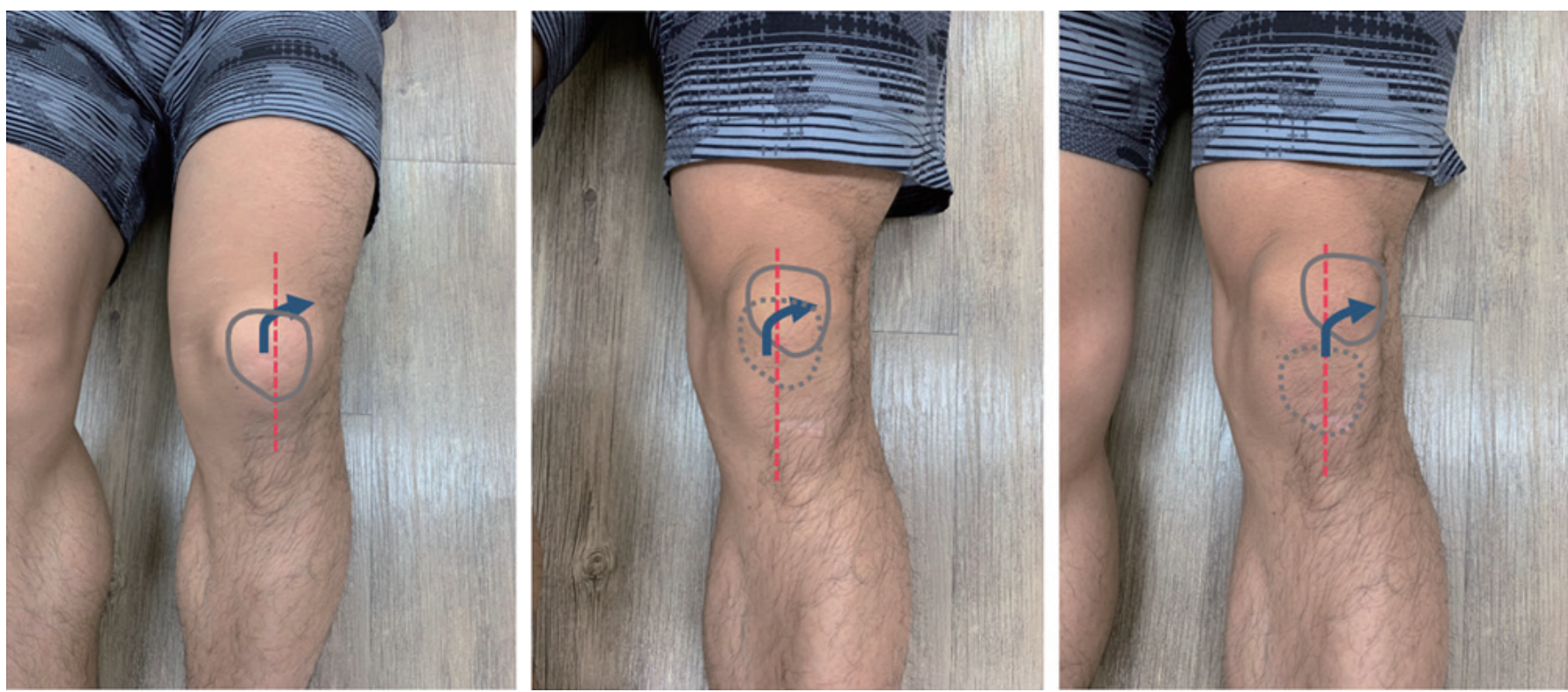

Fig. 1. The "J"-sign, known as the lateral patellar tracking on anterior view of the left knee.

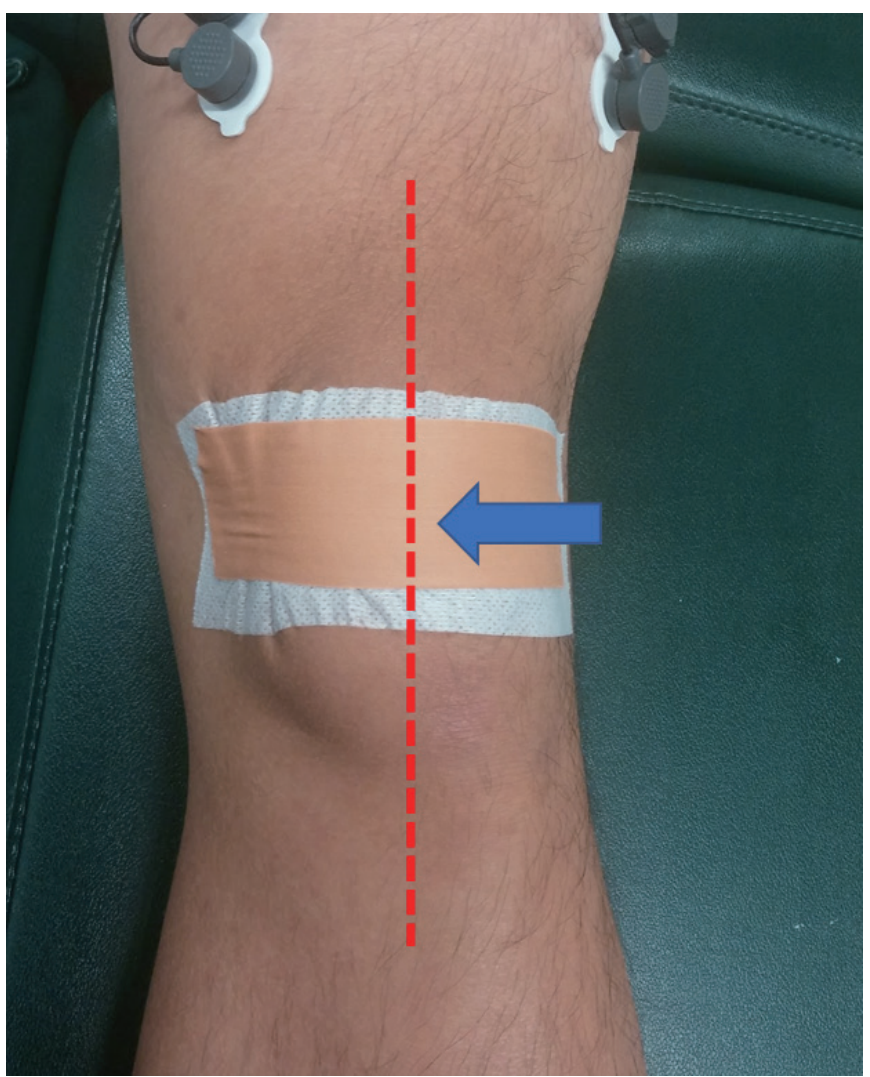

Fig. 2. Standardized McConnell Tape application (The tape holds the realigned patella in place).

\section{McConnell Tape}

McConnell taping was introduced by Jenny McConnell to correct pa- tellar tracking (malalignment) within the femoral trochlea groove and to reduce pain, thereby allowing normal movements of the knee (Fig. 2). This traditional rehabilitation treatment method has been used for PFP and has been reported to relieve pain and improve neuromuscular activity $[12-15]$.

McConnell Taping uses two different tapes: Fixomull ${ }^{\circledR}$ stretch (BSN Inc., Charlotte, NC, USA) and Leukotape $\mathrm{P}^{\circledR}$ (BSN Inc., Charlotte, NC, USA). Leukotape $\mathrm{P}^{\mathbb{R}}$ is a high strength rigid tape with a strong zinc oxide adhesive and Fixomull ${ }^{\circledR}$ stretch is a latex-free cross elastic, non-woven bandage that provides light compression. Even though McConnell taping has been used in clinical settings and has produced successful results, the large volume of controlled research has produced no consistent findings which support its effectiveness [12,16-19].

\section{Pain management and muscle function for McConnell Tape}

A previous research reported that PFP patients who were provided McConnell taping for 2 weeks reported significantly reduced pain scores immediately post-treatment and for a 12-month follow-up test [19]. Also, 79.5\% of subjects achieved normal onset timing of the VMO and VL during the seated knee extension and squat at the 12-month follow-up. Another study examined the electromyography (EMG) activity between VMO and VL in fifteen individuals in an asymptomatic group and thirteen PFP symptomatic group [20]. The EMG activity was measured 
Table 1. Pain management and muscle function for McConnell Tape

\begin{tabular}{|c|c|c|c|}
\hline Reference No. & Author & Year & Result \\
\hline 19 & Paoloni M et al. & 2012 & $\begin{array}{l}\text {-PFP patients who were provided McConnell taping reduced pain socores. } \\
-79.5 \% \text { of subjects achieved normal onset timing of the VMO and VL during the seated knee } \\
\text { extension and squat at the } 12 \text {-month follow-up. }\end{array}$ \\
\hline 20 & Sheehy P et al. & 1998 & $\begin{array}{l}\text {-They found no significant difference between the groups for the VMONVL EMG ratio or for the } \\
\text { onset of peak VMO and VL muscle activity. } \\
\text {-The peak EMG ratio of VMO/VL during the eccentric phase was lower than the concentric phase. }\end{array}$ \\
\hline 12 & Cowan SM et al. & 2002 & $\begin{array}{l}\text {-Showed the application of patellar taping altered the activation of VMO and VL in subjects with } \\
\text { PFP during the same stair stepping task. }\end{array}$ \\
\hline 13 & Christou EA & 2004 & $\begin{array}{l}\text {-The results revealed that medial glide with tape and placebo significantly reduced perceived pain. } \\
\text {-Medial glide significantly increased VMO activity while the activity of VL was decreased. } \\
\text {-There was no significant effect on leg press force. }\end{array}$ \\
\hline 22 & MacGregor K et al. & 2005 & $\begin{array}{l}\text {-Investigated the effect that stretching the skin over the patella had on vasti muscles activity in } \\
\text { people with PFP. }\end{array}$ \\
\hline 24 & Park S et al. & 2010 & -Reported that PFPS patients showed the EMG activation reduction during performing lunge with \\
\hline 25 & Han S and Yoon J & 2008 & external rotation of the foot position to facilitate mor quadriceps muscles. \\
\hline
\end{tabular}

while the subjects utilized the muscles for concentric phase of stair ascent and eccentric phase of stair descent. They found no significant difference between the groups for the VMO/VL EMG ratio or for the onset of peak VMO and VL muscle activity. However, the peak EMG ratio of $\mathrm{VMO} / \mathrm{VL}$ during the eccentric phase (descent) was lower than the concentric phase (ascent). Cowan et al. examined the EMG amplitude of the VMO and VL in individuals with and without PFP during the concentric phase of a stair step-up task [21]. This study had three experimental conditions: no tape, medially directed tape, and vertically directed tape (placebo). It was concluded that medially directed taping significantly decreased pain in subjects with PFP; however, there was no effect on the EMG amplitude of either VMO or VL during the stair step-up task. These results were divergence from those reported by Cowan et al. [12] in an earlier study, which showed that the application of patellar taping altered the activation of VMO and VL in subjects with PFP during the same stair stepping task.

Another study investigated the effect of various patellar taping procedures on force production, EMG activity of the VMO and VL muscles, and perceived pain in females with and without PFP [13]. Data for EMG, pain, and force during maximal isokinetic leg presses at $30 \% \mathrm{sec}$ were collected in a variety of conditions: no tape, no glide (placebo: pes anserinus and fibular head served as the two endpoints) medial glide with tape (pulling the patella medially with tape), and lateral glide (pulling the patella laterally with tape). The results revealed that medial glide with tape and placebo significantly reduced perceived pain. Additionally, medial glide significantly increased VMO activity while the activity of VL was decreased. However, there was no significant effect on leg press force. It was concluded that pain reduction after patellar taping was due to enhanced support of the PF ligaments and/or pain modulation via cutaneous stimulation, and not due to change in the patellar position [13].

Macgregor et al. [22] investigated the effect that stretching the skin over the patella had on vasti muscles activity in people with PFP. Needle electrodes and surface electrodes were used to measure the EMG activity of individual motor units of the VMO and VL during the stretch applied in three different directions using tape. Stretching the skin over the patella increased VMO surface EMG with the greatest increase occurring during lateral stretching [23]. It was concluded that stretching the skin over the patella using tape can increase VMO activity but will have no impact on VL surface EMG activity. Additionally, previous studies also reported that PFPS patients showed the EMG activation reduction during performing lunge with external rotation of the foot position to facilitate more quadriceps muscles [24,25] (Table 1).

\section{Proprioception for McConnell Tape}

Callaghan et al. [18] found that subjects with poor proprioceptive capacity, who had McConnell taping applied to the knee, showed enhancements in active and passive angle proprioception when compared to a 
Table 2. Proprioception for McConnell Tape

\begin{tabular}{lccc}
\hline Reference No. & Author & Year & Result \\
\hline 18 & Callaghan M et al. & 2002 & $\begin{array}{l}\text {-Results demonstrated that poor knee proprioception can be improved using patellar taping and that } \\
\text { application of tape may reduce the risk of injury by enhancing proprioception. }\end{array}$ \\
26 & Chang WD et al. & 2015 & -They concluded that patella taping did not improve AAR and PAR in patients with PFPS. \\
\hline
\end{tabular}

Table 3. Functional task performance for McConnell Tape

\begin{tabular}{llrl}
\hline Reference No. & \multicolumn{1}{c}{ Author } & Year & \multicolumn{1}{c}{ Result } \\
\hline 27 & Selfe J et al. & 2011 & $\begin{array}{l}\text {-It was concluded that McConnell taping and patellar bracing can improve the knee movements } \\
\text { on the coronal and transverse planes during the functional task. }\end{array}$ \\
28 & Cavazzuti L et al. & 2010 & $\begin{array}{l}\text {-There was no significant difference between the onset of the VMO and VL in the healthy group } \\
\text { during the stair stepping task. }\end{array}$ \\
12 & Cowan SM et al. & 2002 & $\begin{array}{l}\text {-This supports the relationship between delayed onset of activity by the vasti muscles and PFP. } \\
16\end{array}$ \\
& Aminaka N and Gribble PA & 2008 & $\begin{array}{l}\text {-The PFP group with McConnell tape showed a reduction in knee pain and improvement in } \\
\text { balance compared to a no-tape condition. } \\
\text {-There were no significant differences in hip and knee angles in the sagittal plane. }\end{array}$ \\
\hline
\end{tabular}

condition where not tape was applied. Subjects were subdivided into $\operatorname{good}\left(\leq 5^{\circ}\right)$ and bad $\left(>5^{\circ}\right)$ proprioceptive groups based on their abilities to reproduce target angle positions. Results demonstrated that poor knee proprioception can be improved using patellar taping and that application of tape may reduce the risk of injury by enhancing proprioception.

A previous investigation examined the effect of patella taping of the proprioceptive status of patients with PFPS $(\mathrm{N}=32)$ [26]. They assessed active (AAR) and passive (PAR) angle reproduction at an angular velocity of $2^{\circ} / \mathrm{sec}$ with a start angle at $90^{\circ}$. The target angle to assess AAR and PAR was $60^{\circ}$ and $20^{\circ}$. Ten subjects were graded good proprioception ( $<5^{\circ}$ from target angles) and twenty-two subjects were graded poor proprioception ( $>5^{\circ}$ from target angles) after taping application. They concluded that patella taping did not improve AAR and PAR in patients with PFPS (Table 2).

\section{Functional task performance for McConnell Tape}

In addition to the research examining pain, pain-limited range of motion, and neuromuscular performance, studies have also examined the effects of these tapes on muscle activity and joint kinematics during functional task performance including gait and stair-stepping. Selfe et al. [27] utilized no tape, patellar bracing, and McConnell taping to examine potential modifications in knee kinematics in PFP during stair descent. They showed a significant reduction for knee range of motion in the coronal plane with the McConnell taping; while the knee range of motion in the transverse plane was significantly decreased with the patellar bracing. It was concluded that McConnell taping and patellar bracing can improve the knee movements on the coronal and transverse planes during the functional task.

Similarly, another study compared the muscle activity between VMO and VL in PFP during the functional task of stair stepping [28]. They found that the onset of the VL started before the VMO in both stair ascent (concentric contraction) and descent (eccentric contraction). In contrast, there was no significant difference between the onset of the VMO and VL in the healthy group during the stair stepping task. This supports the relationship between delayed onset of activity by the vasti muscles and PFP [12].

Finally, a study conducted by Aminaka and Gribble [16] examined the effects of McConnell taping on knee pain and hip and knee kinematics in the sagittal plane during dynamic balance testing. The PFP group with McConnell tape showed a reduction in knee pain and improvement in balance compared to a no-tape condition. However, there were no significant differences in hip and knee angles in the sagittal plane. The authors concluded that McConnell taping provides benefits for knee pain and balance in PFP, but the exact mechanism cannot be explained (Table 3).

\section{CONCLUSION}

Understanding effectiveness and mechanism of McConnell taping should be made as much as possible, as no clinical professionals will deny that McConnell taping cannot be used without evidence. Also, there is extremely limited evidence on relationship between McConnell taping and proprioception. Because of controversial findings in the areas 
of conservative approaching in treatment for knee pain, it is recommended that future investigations into McConnell taping should focus on these factors.

\section{CONFLICTS OF INTEREST}

The authors declare no conflict of interest.

\section{AUTHOR CONTRIBUTIONS}

Review topic and study design: HJ; drafting of the manuscript: HJ, and EC; critical revision of the manuscript: HJ, and EC; administrative, technical, or material support: EC; and study supervision: HJ.

\section{ORCID}

Hyung-pil Jun https://orcid.org/0000-0001-7772-8276

Eunwook Chang https://orcid.org/0000-0001-5876-9275

\section{REFERENCES}

1. Taunton JE, Ryan MB, Clement DB, McKenzie DC, Lloyd-Smith DR, et al. A retrospective case-control analysis of 2002 running injuries. $\mathrm{Br}$ J Sports Med. 2002;36(2):95-101.

2. Raid D. The myth, mystic, and frustration of anterior knee pain. Clin J Sport Med. 1993;3(3):139-43.

3. Wallace DA, Salem GJ, Salinas R, Powers CM. Patellofemoral joint kinetics while squatting with and without an external load. J Orthop Sports Phys Ther. 2002;32(4):141-8.

4. Cowan SM, Crossley KM, Bennell KL. Altered hip and trunk muscle function in individuals with patellofemoral pain. Br J Sports Med. 2009; 43(8):584-8.

5. Emami MJ, Ghahramani MH, Abdinejad F, Namazi H. Q-angle: an invaluable parameter for evaluation of anterior knee pain. Arch Iran Med. 2007;10(1):24-6.

6. Powers CM. The influence of abnormal hip mechanics on knee injury: A biomechanical perspective. J Orthop Sports Phys Ther. 2010;40(2): 42-51.

7. Powers CM, Landel R, Perry J. Timing and intensity of vastus muscle activity during functional activities in subjects with and without patellofemoral pain. Phys Ther. 1996;76(9):946-55.
8. Levinger P, Gilleard W. Tibia and rearfoot motion and ground reaction forces in subjects with patellofemoral pain syndrome during walking. Gait Posture. 2007;25(1):2-8.

9. Mizuno Y, Kumagai M, Mattessich SM, Elias JJ, Ramrattan N, et al. Qangle influences tibiofemoral and patellofemoral kinematics. J Orthop Res. 2001;19(5):834-40.

10. Witvrouw E, Lysens R, Bellemans J, Cambier D, Vanderstraeten G. Intrinsic risk factors for the development of anterior knee pain in an athletic population: A two-year prospective study. Am J Sports Med. 2000; 28(4):480-9.

11. Cerny K. Vastus medialis oblique/vastus lateralis muscle activity ratios for selected exercises in persons with and without patellofemoral pain syndrome. Phys Ther. 1995;75(8):672-83.

12. Cowan SM, Bennell KL, Hodges PW. Therapeutic patellar taping changes the timing of vasti muscle activation in people with patellofemoral pain syndrome. Clin J Sport Med. 2002;12(6):339-47.

13. Christou EA. Patellar taping increases vastus medialis oblique activity in the presence of patellofemoral pain. J Electromyogr Kinesiol. 2004; 14(4):495-504

14. Ng GYF, Cheng JMF. The effects of patellar taping on pain and neuromuscular performance in subjects with patellofemoral pain syndrome. Clin Rehabil. 2002;16(8):821-7.

15. Salsich GB, Brechter JH, Farwell D, Powers CM. The effects of patellar taping on knee kinetics, kinematics, and vastus lateralis muscle activity during stair ambulation in individuals with patellofemoral pain. J Orthop Sports Phys Ther. 2002;32(1):3-10.

16. Aminaka N, Gribble PA. Patellar taping, patellofemoral pain syndrome, lower extremity kinematics, and dynamic postural control. J Athl Train. 2008;43(1):21-8.

17. Bennell K, Duncan M, Cowan S. Effect of patellar taping on vasti onset timing, knee kinematics, and kinetics in asymptomatic individuals with a delayed onset of vastus medialis oblique. J Orthop Res. 2006; 24(9):1854-60.

18. Callaghan MJ, Selfe J, Bagley PJ, Oldham JA. The effects of patellar taping on knee joint proprioception. J Athl Train. 2002;37(1):19-24.

19. Paoloni M, Fratocchi G, Mangone M, Murgia M, Santilli V, et al. Long-term efficacy of a short period of taping followed by an exercise program in a cohort of patients with patellofemoral pain syndrome. Clin Rheumatol. 2012;31(3):535-9.

20. Sheehy P, Burdett RG, Irrgang JJ, VanSwearingen J. An electromyographic study of vastus medialis oblique and vastus lateralis activity while 
ascending and descending steps. J Orthop Sports Phys Ther. 1998;27(6): 423-9.

21. Cowan SM, Hodges PW, Crossley KM, Bennell KL. Patellar taping does not change the amplitude of electromyographic activity of the vasti in a stair stepping task. Br J Sports Med. 2006;40(1):30-4.

22. MacGregor K, Gerlach S, Mellor R, Hodges PW. Cutaneous stimulation from patella tape causes a differential increase in vasti muscle activity in people with patellofemoral pain. J Orthop Res. 2005;23(2):351-8.

23. Van Tiggelen D, Cowan S, Coorevits P, Duvigneaud N, Witvrouw E. Delayed vastus medialis obliquus to vastus lateralis onset timing contributes to the development of patellofemoral pain in previously healthy men: A prospective study. Am J Sports Med. 2009;37(6):1099-105.

24. Park S, Lee M, Choi S. Comparison of electromyographic activity of quadriceps during lunge according to ankle position in ssireum players with patellofemoral pain syndrome. Exerc Sci. 2010;19(3):219-30.
25. Han S, Yoon J. Effect of rehabilitation exercise and backward walking and neuromuscular electrical stimulation on the quadriceps muscle function in patients with patellofemoral pain pyndrome. Exerc Sci. 2008;17(4):463-72.

26. Chang WD, Chen FC, Lee CL, Lin HY, Lai PT. Effects of kinesio taping versus McConnell taping for patellofemoral pain syndrome: a systematic review and meta-analysis. Evid Based Complement Alternat Med. 2015;471208.

27. Selfe J, Thewlis D, Hill S, Whitaker J, Sutton C, et al. A clinical study of the biomechanics of step descent using different treatment modalities for patellofemoral pain. Gait Posture. 2011;34(1):92-6.

28. Cavazzuti L, Merlo A, Orlandi F, Campanini I. Delayed onset of electromyographic activity of vastus medialis obliquus relative to vastus lateralis in subjects with patellofemoral pain syndrome. Gait Posture. 2010;32(3):290-5. 